Кильдюшева Ольга Александровна

кандидат социологических наук, доцент кафедры гуманитарных и социально-экономических дисциплин Средне-Волжского института (филиала) Всероссийского государственного университета юстиции (РПА Минюста России) в городе Саранске

\section{ОСОБЕННОСТИ ФЕНОМЕНА БЕДНОСТИ НА СОВРЕМЕННОМ ЭТАПЕ РАЗВИТИЯ РОССИЙСКОГО ОБЩЕСТВА}

Аннотация:

В статье рассматривается феномен бедности в постсоветской России. Выявлена проблема отсутствия общепринятого определения понятия "бедность" ввиду сложносоставного характера исследуемого феномена и, как следствие, единой методологии измерения данного явления. Обозначена неэффективность измерения бедности с использованием абсолютного подхода. Опираясь на имеющиеся публикации, материалы официальной статистики и действующие нормативно-правовые акты, автор выделяет особенности феномена бедности в современном российском обществе.

Ключевые слова:

бедность, абсолютная бедность, прожиточный минимум, средний душевой денежный доход, дифференциация населения, социальное неравенство, социальный состав, национальная безопасность.

\section{Kildyusheva Olga Aleksandrovna}

PhD in Social Science, Assistant Professor, Humanities, Social and Economic Sciences Department, Middle Volga Institute, Saransk Branch of Russian University of Justice

(Russian Academy of Law of the Ministry of Justice of the Russian Federation)

\section{FEATURES OF THE POVERTY PHENOMENON AT THE PRESENT STAGE OF THE RUSSIAN SOCIETY DEVELOPMENT}

Summary:

The article discusses the phenomenon of poverty in post-Soviet Russia. The paper identifies the problem of lack of the common definition for "poverty" in view of the complex nature of the investigated phenomenon and, as a result, a unified methodology of measuring this phenomenon. The research finds inefficiency of measuring poverty by applying absolute approach. Based on the publications which are available on this subject, materials of official statistics and the existing laws and regulations, the author defines features of the poverty phenomenon in the modern Russian society.

Keywords: poverty, absolute poverty, living wage, average income, population differentiation, social inequality, social structure, national security.

Бедность - одна из негативных проблем любой страны. В истории человечества не было общества, в которой бы ее не существовало. Этот феномен тесно связан с экономическим развитием страны, проводимой социальной политикой и безопасностью государства. Именно поэтому, несмотря на большое количество исследований и научных работ по данной теме, она попрежнему остается актуальной.

В современной социологической науке отсутствует единая общепринятая дефиниция понятия бедности. Более того, в разные периоды доминировали социальные либо экономические аспекты данного общественного явления, при которых учитывались недостаточность экономических ресурсов либо определенный образ жизни. Но сегодня невозможно рассматривать бедность с какой-то одной стороны, что обусловлено ее сложносоставным характером, подразумевающим присутствие социальных, экономических, политических и духовных аспектов.

Многочисленные исследования бедности, проведенные учеными со всего мира, позволили выявить ряд ее характерных признаков:

1. Бедные являются внутренне неоднородной группой. К ним относятся те, кто испытывает постоянную нужду, кто балансирует между бедными и небедными и кто стали бедными в результате преобразований в экономике.

2. Основа бедных - жители сельской местности.

3. Боेльшая часть бедных проживает в неблагоприятных экологических условиях.

4. Бедность имеет «женское лицо» [1].

Вместе с тем, несмотря на существенные сходные признаки данного явления, имеются и отличительные особенности, присущие той или иной стране. Бедность в условиях российского общества отличается по таким критериям, как причины, степень распространенности и продолжительность.

Так, видный представитель русской философии П.Я. Чаадаев, анализируя причины отсталости России от Западной Европы, указывал на следующие: географическое положение, христианство в его византийской форме, монголо-татарское нашествие. Перечисленное можно рассматривать и в качестве основных исторических предпосылок бедности, к которым следует еще 
отнести крепостное право. А с распадом СССР и трансформацией российского общества бедность приобрела беспрецедентные степень распространенности и продолжительность.

Обращаясь к данным статистики, следует отметить, что в 1995 г. уровень бедности в России составлял 24,8 \% [2]. Пик уровня бедности пришелся на 1998-1999 гг. Финансовый кризис 1998 г. привел к тому, что численность населения с доходами ниже прожиточного минимума составила 47 \% населения страны, а годом позже достигла 56 \% [3]. При этом социальный состав бедного населения был представлен теми категориями граждан, которые должны формировать фундамент среднего слоя, а именно пенсионеры и работники бюджетной сферы, в том числе врачи и учителя.

К 2010 г. численность бедного населения в стране сократилась и составила 12,5\%. В это же время подошел к концу двадцатипятилетний период масштабных реформ и процесс фрормирования новой социальной структуры. В этот период ученые высказывали надежду, что в результате преобразований Россия сможет поддерживать внутреннюю стабильность и быть конкурентоспособной на международной арене, но вместе с тем не отрицали и того, что в стране углубляется социальная дифференциация и нарастает социальное неравенство, обесценивающее все достижения последних лет [4].

В 2015 г. показатель бедности незначительно увеличился и стал равен 13,3 \% [5]. Причинами выступили новые вызовы для российского общества, среди которых экономические санкции. В ответ на сложившуюся ситуацию в конце декабря 2015 г. принимается нормативно-правовой акт «О стратегии национальной безопасности Российской Федерации» [6], согласно которому бедность - угроза национальной безопасности, а для снижения ее уровня необходим рост доходов населения.

Уровень доходов населения является одним из наиболее важных социальных факторов, влияющих на качество жизни (табл. 1).

Таблица 1 - Динамика основных показателей уровня жизни населения России [7]

\begin{tabular}{|c|c|c|c|c|c|}
\hline Показатели & 1995 & 2000 & 2005 & 2010 & 2015 \\
\hline Денежные доходы (в среднем на душу населения в месяц), р. & 516 & 2281 & 8112 & 18881 & 30225 \\
\hline Покупательная способность среднедушевого денежного дохода, \% & 195 & 198 & 269 & 333 & 312 \\
\hline $\begin{array}{l}\text { Среднемесячная начисленная заработная плата работающих } \\
\text { в экономике, р. }\end{array}$ & 472,4 & 2223 & 8555 & 20952 & 34030 \\
\hline Покупательная способность среднемесячной заработной платы, \% & 159 & 168 & 263 & 341 & 325 \\
\hline Средний размер начисленных пенсий (в месяц), р. & 188,1 & 694,3 & 2364 & 7476 & 11986 \\
\hline Покупательная способность средней пенсии, \% & 101 & 76 & 98 & 165 & 151 \\
\hline Децильный коэфффициент фондов & 13,5 & 13,9 & 15,2 & 16,6 & 15,6 \\
\hline Величина прожиточного миним & 264,1 & 1210 & 3018 & 5688 & 9701 \\
\hline
\end{tabular}

Согласно данным таблицы 1 можно говорить о постепенном сокращении покупательной способности населения в период 2010-2015 гг., несмотря на увеличение размера пенсий, заработной платы и др. На продолжающуюся поляризацию общества указывает децильный коэффрициент фрондов, отражающий дифференциацию доходов населения или социально-экономическое неравенство. Он входит в число основных показателей, необходимых для оценки состояния национальной безопасности, и для развитых западных стран не превышает 4-5 раз.

Большой интерес представляет рассмотрение социального состава бедных в 2015 г. Так, по демографическим признакам большую часть бедных (40 \%) составляли люди трудоспособного возраста - мужчины в возрасте 31-59 лет и женщины в возрасте 31-54 года (20 и 20 \% соответственно), проживающие в городской местности (примерно 60 \%). По уровню образования бедных можно сделать неутешительный вывод: большинство из них имеют среднее профессиональное образование (35-42,3 \%). Большая часть бедных занята в экономике и составляет 63,8 \%, а число безработных бедных равняется 2,8 \% [8]. Такие показатели указывают на низкий уровень доходов, а в первую очередь на низкую заработную плату, не гарантирующую минимального прожиточного минимума (9 701 р.) [9] на каждого члена семьи.

В последнее время происходит поступательное увеличение размера заработной платы, пенсий и иных социальных выплат, но их рост нивелируется уровнем инфрляции, а проблема низкого уровня доходов населения по-прежнему остается актуальной. По этой причине руководством страны для решения вопроса об обеспечении национальной безопасности ставятся задачи содействия сокращению бедности.

Анализируя сложившуюся ситуацию с феноменом бедности в современном российском обществе, необходимо указать на несовершенство методики измерения бедности, основанной на абсолютном подходе. Согласно абсолютной теории бедным считается население с доходами ниже прожиточного минимума, величина которого устанавливается с учетом потребительской корзины [10, ст. 4] и сегодня не отражает реальных потребностей населения. Например, в 2006 г. 
бедных в стране по данным Росстата было 15,2 \%, а директор Всероссийского центра уровня жизни В. Бобков приводит следующие данные: треть населения России составляли бедные, еще одну треть - низко- и среднеобеспеченные, только около $10 \%$ - состоятельные и богатые. По данным Института социологии РАН, в 2006 г. более трети населения России жило за порогом или на грани бедности, а 7 \% находились в состоянии крайней бедности, глубокой нищеты. Еще 14 \% бедных фрактически также прочно «застряли» в этом состоянии. Кроме того, 17 \% населения пребывает в состоянии постоянного риска бедности, хотя пока им удается удерживаться «на плаву», балансируя на грани бедности и малообеспеченности, и численность этой «группы риска» возрастает [11].

Подобных взглядов на использование абсолютной теории бедности придерживаются и европейские специалисты. Так, по мнению доктора экономики, научного сотрудника Европейского института профсоюзов (Брюссель) Д. Буже, «нищие на улице, бездомные, дети, страдающие от недоедания, увеличение числа больных с инфекционными заболеваниями прошлой эры (туберкулез и т. д.) являются видимыми, усиливающимися признаками крайней бедности в европейских странах. Это напоминает картину бедности из предыдущих веков, предшествовавшую национальному экономическому развитию и введению систем социального обеспечения в Европе. ...Коллективная надежда на исчезновение абсолютной бедности постепенно исчезала. Избавившись однажды от абсолютной бедности, мы вновь вынуждены исследовать это понятие, которое уже было подвергнуто серьезной критике в 1960-1970-х. Сегодня мы отмечаем, что фундаментальные потребности снова стали составляющими понятия бедности. ...Существует тесная связь между потребностями и бедностью, особенностями этих потребностей и измерением абсолютной бедности. Основной категорией здесь выступает еда, которая является основной жизненно важной потребностью. Однако независимо от способа - теоретического или эмпирического - рассмотрения феномена абсолютной бедности согласно потребностям (включая жизненно важные) очевидно, что подобный анализ не позволит получить достоверную и полную картину, вследствие чего делаем вывод, что абсолютная бедность на самом деле является относительным показателем...» [12].

Таким образом, бедность присуща любому обществу и имеет общие характерные черты. Но любая степень сходства всегда предполагает определенные различия, что применительно к России проявляется не только в наличии исторических предпосылок и масштабов рассматриваемого феномена. Важно отметить, что отсутствие сегодня единого понимания бедности ведет к отсутствию единой методики измерения данного негативного явления. Этим можно объяснить существенные различия результатов исследований, построенных на официальных данных и данных, полученных в ходе опросов общественного мнения. Число бедных изменяется также при использовании разных методов измерения бедности, что свидетельствует о спорности любого из них. Следовательно, наиболее эффрективной является комбинированная методика исследования бедности, основанная на сочетании нескольких концепций бедности. Главное при этом разработать методологию для определения, кого можно назвать бедным и как вычислить тот уровень, за которым начинается бедность.

\section{Ссылки и примечания:}

1. Попова М.Б. Социальная диффреренциация и бедность населения. Петрозаводск, 1998. С. 70-71

2. Основные социально-экономические характеристики Российской Федерации [Электронный ресурс] // Российский статистический ежегодник - 2012. URL: http://www.gks.ru/bgd/regl/b12_13/lssWWW.exe/Stg/d1/01-01.htm (дата обращения: 26.01.2017).

3. Лайкам К. Государственные меры по регулированию дифференциации доходов населения и снижению уровня бедности // Общество и экономика. 2002. № 12. С. 30-49.

4. Горшков М.К. Реформы в зеркале общественного мнения // Социологические исследования. 2011. № 10. С. 6 ; Козырева П.М. Социальная адаптация населения России в постсоветский период // Там же. № 6. С. 32 ; Тихонова Н.Е. Низший класс в социальной структуре российского общества // Там же. № 5. С. 24.

5. Социально-экономические индикаторы бедности в 2012-2015 гг. [Электронный ресурc]. URL: http://www.gks.ru/bgd/regl/b16_110/Main.htm (дата обращения: 14.01.2017).

6. О стратегии национальной безопасности Российской Федерации : указ Президента от 31 дек. 2015 г. № 683 // Собрание законодательства РФ. 2016. № 1 (ч. ІІ). Ст. 212.

7. Составлено по данным Росстата.

8. Социально-экономические индикаторы ...

9. Там же.

10. О прожиточном минимуме в Российской Федерации : федер. закон от 24 окт. 1997 г. № 134-Ф3 // Собрание законодательства РФ. 1997. № 43. Ст. 4904.

11. Симонян Р.Х. Реформы 1990-х годов и современная социальная структура российского общества (к 20-летию экономических реформ) // Социологические исследования. 2012. № 1. С. 41

12. Bouget D. Needs and the Concept of Absolute Poverty: Incompleteness and Relativism // Absolute Poverty in Europe. Salzburg, 2015. P. 24-25. 


\section{References:}

Bouget, D 2015, 'Needs and the Concept of Absolute Poverty: Incompleteness and Relativism', Absolute Poverty in Europe, Salzburg, pp. 24-25.

Gorshkov, MK 2011, 'Reforms in the reflection of public opinion', Sotsiologicheskiye issledovaniya, no. 10, p. 6, (in Russian).

Kozyreva, PM 2011, 'Social adaptation of the population of Russia in the post-Soviet period', Sotsiologicheskiye issledovaniya, no. 6, p. 32, (in Russian).

Laikam, K 2002, 'State measures to regulate the differentiation of population income and poverty reduction', Obshchestvo $i$ ekonomika, no. 12, pp. 30-49, (in Russian).

'Main social and economic features of the Russian Federation' 2017, Rossiyskiy statisticheskiy yezhegodnik - 2012, viewed 26 January 2017, <http://www.gks.ru/bgd/regl/b12_13/lssWWW.exe/Stg/d1/01-01.htm>, (in Russian).

'On the subsistence level in the Russian Federation: Federal Law as of October 24, 1997 no. 134-FZ' 1997, Sobraniye zakonodatel'stva RF, no. 43, Art. 4904, (in Russian).

Popova, MB 1998, Social differentiation and population poverty, Petrozavodsk, pp. 70-71, (in Russian).

Simonyan, RKh 2012, 'Reforms of the 1990s and the current social structure of Russian society (towards the 20th anniversary of economic reforms)', Sotsiologicheskiye issledovaniya, no. 1, p. 41, (in Russian).

Tikhonova, NE 2011, 'The lowest class in the social structure of Russian society', Sotsiologicheskiye issledovaniya, no. 5, p. 24, (in Russian). 